\title{
Mate searching in the scale insect, Dactylopius coccus (Hemiptera: Coccoidea: Dactylopiidae)
}

\author{
Luis C. RODRÍGUEZ, ERIC H. FAÚNDEZ and HERMANN M. NIEMEYER \\ Departamento de Ciencias Ecológicas, Facultad de Ciencias, Universidad de Chile, Casilla 653, Santiago, Chile; \\ e-mail: niemeyer@abulafia.ciencias.uchile.cl
}

Key words. Dactylopius coccus, sex pheromone, chemical communication, Opuntia ficus indica

\begin{abstract}
Dactylopius coccus is a sessile scale insect living on cladodes of Opuntia ficus indica which has commercial importance as a source of carminic acid. We herein present behavioural evidence of the existence of a sex pheromone in $D$. coccus, based on olfactometric experiments using both biological sources of odours and collected chemical extracts.
\end{abstract}

\section{INTRODUCTION}

The coccid Dactylopius coccus Costa is an insect living on cladodes of prickly pears (Opuntia ficus indica). Dried females are a source of red dyes widely utilised in the food, textile and pharmaceutical industries (Méndez et al., 2004). During their life cycle, insects are able to disperse only during the first nymphal stage, becoming sessile thereafter. Female insects pass through a second nymphal stage before becoming adults, while males produce a cocoon within which prepupal and pupal stages develop before adult emergence (Pérez Guerra \& Kosztarab, 1992). In contrast with most members of the superfamily Coccoidea, D. coccus has solely sexual reproduction. Cochineal colonies exhibit overlapping generations, where females at different life stages co-exist (Flores-Flores \& Teckelenburg, 1995). Emerging males should be able to recognise cladodes with cochineal colonies, and further identify the recently emerged females in order to mate. There is growing evidence of the importance of chemical communication in the success or failure of scale insects to mate (e.g. Zada et al., 2004), including the reduction in the emission of sex pheromones after mating (e.g. Mendel et al., 1990). We herein present evidence of the existence of a sex pheromone in D. coccus based on olfactometric experiments using cladodes, cladodes with cochineal colonies, females at different life stages, and female produced volatiles.

\section{MATERIAL AND METHODS}

A four-arm olfactometer was used (Pettersson, 1970). Each couple of opposing arms was connected with Teflon tubing to a glass belljar containing a stimulus (see below). Charcoal filters at the inlet of the belljars eliminated external odours. Air (250 $\mathrm{ml} / \mathrm{min}$ ) was pumped out from the arena through a hole in its centre. Recently emerged males were used as test individuals. Observations were made continuously for 15 minutes, and the total time they spent in the arms with different stimuli was determined and compared with the Wilcoxon test for paired data (Siegel \& Castellan, 1988). Fifteen replicates were performed for each treatment

The stimuli were: clean cladodes, cladodes infested with a coccid colony containing ca. 300 individuals, cladodes with ca. 100 ovipositing females, cladodes with ca. 100 recently emerged females, recently emerged females withdrawn from colonies (ca. 100 individuals), and volatiles collected from recently emerged females.

Air was pushed at a flow of $400 \mathrm{ml} / \mathrm{min}$ during $72 \mathrm{~h}$ through a glass container containing a colony of ca. 200 recently emerged females. Volatiles entrained were collected in a column containing $30 \mathrm{mg}$ Porapak Q and eluted with $3 \mathrm{ml}$ dichloromethane. The extract was concentrated to $150 \mu 1$ under a stream of nitrogen. Ten $\mu 1$ of the concentrated extract were blotted on a filter paper which was placed in the stimulus belljar of the olfactometer. Ten $\mu 1$ of the solvent were blotted on another filter paper which was placed inside the control belljar.

\section{RESULTS AND DISCUSSION}

Table 1 summarises the results of the different olfactometric experiments. Dactylopius coccus males did not show preference

TABLE 1. Olfactometric response of males of Dactylopius coccus towards different stimuli. In all cases, $\mathrm{n}=15$. Level of accepted significance: $\mathrm{p}<0.05$, Wilcoxon test for paired comparisons.

\begin{tabular}{lcc}
\hline Contrasting stimuli & Average time in olfactometer arm (min) & $\mathrm{p}$ \\
\hline Cladode vs. & $5.10 \pm 4.20$ & 0.852 \\
Nothing & $4.79 \pm 2.96$ & $<0.01$ \\
Cladode with coccid colony vs. & $10.02 \pm 2.23$ & \\
Uninfested cladode & $1.18 \pm 1.28$ & $<0.03$ \\
Cladode with recently emerged females vs. & $7.70 \pm 3.84$ & $<0.01$ \\
Cladode with ovipositing females & $3.75 \pm 2.85$ & $<.26 \pm 2.77$ \\
Recently emerged females vs. & $1.95 \pm 2.32$ & $<0.01$ \\
Blank & $10.24 \pm 3.74$ & $1.53 \pm 1.66$ \\
Extract of volatiles collected from recently emerged females vs. & & \\
Solvent & &
\end{tabular}


for the uninfested Opuntia cladodes, but responded preferentially towards volatiles from cladodes with colonies over clean cladodes, to cladodes with recently emerged females relative to ovipositing females, to isolated recently emerged females, and to volatiles collected from the latter. Evidence for the existence of chemical communication in members of the genus Dactylopius has not been reported previously. In other scale insects, such as Planococcus ficus, a sex pheromone has been identified (Zada et al., 2003), providing a turning point for the development of management and monitoring techniques. The subsequent isolation and synthesis of the chemical compound involved in mate searching in $D$. coccus could provide a future tool for the improvement of the commercial production of this valuable insect.

ACKNOWLEDGEMENTS. We thank the financial support of Fondo para la Innovación Agraria, project V99-O-A-017.

\section{REFERENCES}

Flores-Flores V. \& Teckelenburg A. 1995: Dacti (Dactylopius coccus) dye production. In Barbera G. (ed.): Agro-ecology, Cultivation and Uses of Cactus Pear. Plant Production and Protection Paper 132. FAO, Rome, pp. 167-185.

Mendel Z., Dunkelblum E. \& Robinson D. 1990: Sexual behavior of Matsucoccus josephi (Homoptera: Margaro- didae). Asynchronous adult male emergence and release of female sex pheromone J. Chem. Ecol. 16: 2341-2352

Méndez J., González M., Lobo M.G. \& Carnero A. 2004: Color quality of pigments in cochineals (Dactylopius coccus Costa). Geographical origin characterization using multivariate statistical analysis. J. Agric. Food Chem. 52: 1331-1337.

Pérez Guerra G. \& Kosztarab M. 1992: Biosystematics of the family Dactylopiidae (Homoptera: Coccinea) with emphasis on the life cycle of Dactylopius coccus Costa. Studies on the morphology and systematics of scale insects No. 16. Virginia Agricultural Experimental Station (VAES) Bulletin 92: vi +90 pp.

Pettersson J. 1970: An aphid sex attractant, 1. Biological studies. Entomol. Scand. 1: 63-73.

Siegel S. \& Castellan N.J. 1988: Nonparametric Statistics for the Behavioral Sciences. 2nd ed. McGraw-Hill, Singapore, 399 pp.

Zada A., Dunkelblum E., Assael F., Harel M., Cojocaru M. \& Mendel Z. 2003: Sex pheromone of the vine mealybug, Planococcus ficus in Israel: occurrence of a second component in a mass-reared population. J. Chem. Ecol. 29: 977-988.

Zada A., Dunkelblum E., Habel M., Assael F., Gross S. \& Mendel Z. 2004: Sex pheromone of the citrus mealybug Planococcus citri: synthesis and optimization of trap parameters J. Econ. Entomol. 97: 361-368

Received May 14, 2004; revised July 15, 2004; accepted August 25, 2004 